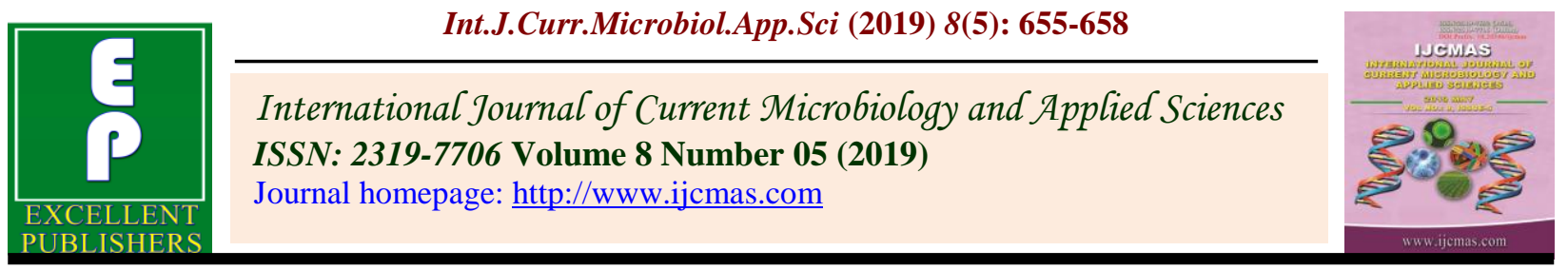

Original Research Article

https://doi.org/10.20546/ijcmas.2019.805.076

\title{
Screening of Promising Sorghum Genotypes against Turcicum Leaf Blight (Exserohilum turcicum (Pass.) Leonard and Suggs) under Glasshouse Conditions
}

\author{
Raghavender Yelgurty $^{1 *}$, S.K. Jayalkshmi², B. Zaheer Ahamed ${ }^{3}$, \\ Shreedevi S. Chavan ${ }^{4}$ and G. Girish ${ }^{4}$ \\ ${ }^{1}$ Department of Plant Pathology, College of Agriculture, \\ University of Agricultural Sciences, Raichur-584104, Karnataka, India \\ ${ }^{2}$ Department of Plant Pathology, College of Agriculture, \\ Kalaburagi - 585101, Karnataka, India \\ ${ }^{3}$ Department of Plant Pathology, ICAR-Krishi Vigyan Kendra, Kalaburagi-585101, \\ Karnataka, India \\ ${ }^{4}$ Department of Genetics and plant breeding, College of Agriculture, University of \\ Agricultural Sciences, Raichur-584104, Karnataka, India \\ *Corresponding author
}

A B S T R A C T

\section{Keywords}

Sorghum, Turcicum leaf blight, Screening, Exerohilum turcicum

Article Info

Accepted:

10 April 2019

Available Online:

10 May 2019
Sorghum (Sorghum bicolor Linn. Moench) popularly known as Jowar, is the major cereal consumed in India and ranks fifth after wheat, rice, maize and pearl millet. A total of 23 sorghum genotypes were screened for their reaction against turcicum leaf blight under glass house condition. Out of 23 genotypes screened, four showed resistant reaction (Grade-2) viz., J-P-1-5, J-9, IS-2312 and C-42. Whereas M 35-1, J-33, J-3-1, J-4-1, Chincholli, GS-23, E-36-1, J-35, C-35, J-9-12, J-6-2, J-11, C-30, J-8 and C-28 showed moderately resistant reaction (Grade-3) and remaining four genotypes viz., DSV-4, SPV-86, DJ-6514, H-112 recorded susceptible reaction (Grade-4).

\section{Introduction}

Sorghum (Sorghum bicolor Linn. Moench) popularly known as Jowar, is the major cereal consumed in India and ranks fifth after wheat, rice, maize and pearl millet. The world production of grain sorghum is 70.83 million tons from 44.8 million ha area of land (FAOSTAT, 2014). India is major producer of sorghum, ranks fifth after, wheat, rice, maize and pear millet cultivated in 6.16 million hectares in both kharif (2.26m.ha) and rabi $(3.89 \mathrm{~m}$. ha) with an annual production of 5.44 million tons of grain with productivity of $8.44 \mathrm{~kg}$ per hectare (INDIASTAT, 2015).

In India the sorghum is cultivated in Maharashtra, Karnataka and Andhra Pradesh as rainfed crop to an extent of 85 per cent (4.93m.ha). In Karnataka sorghum production 
is about 1.32 million tons in an area of 1.04 million ha with the average productivity of $1180 \mathrm{~kg}$ per ha. The sorghum is the main food crop of Hyderabad-Karnataka region and occupies an area of 5.6 lakh hectares with production of 5.5 lakh tons and productivity of 1122kg per ha (Anon., 2014-15).

As the rabi sorghum produces the white pearly grains which is mainly used for food in India for the preparation of roti. It is also an important animal feed (swine, poultry and cattle) used in countries like U.S., Mexico, South America and Australia. Sorghum, as a food, feed and bio fuel crop with excellent drought resistance compared to other cereals, is considered as a "failsafe crop" (Burke et al., 2010).

Sorghum grain is a principal source of energy, protein, vitamins and minerals for the poor people living in the semi-arid tropics. It is nutritionally superior to rice because of its high mineral and fiber content. Starch (60$75 \%$ ) is the main component of sorghum grain, followed by proteins (7-15\%), nonstarch polysaccharides (2-7\%) and fat (1.5$6 \%)$.The average energetic value of whole sorghum grain flour is $356 \mathrm{kcal} / 100 \mathrm{gm}$ (Dicko et al., 2006). Sorghum is a good source of vitamins, notably the $\mathrm{B}$ vitamins (thiamin, riboflavin, pyridoxine and niacin) and the liposoluable vitamins A, D, E and $\mathrm{K}$. Unique property of sorghum grain makes it well suited to prepare various food items such as porridge, unleavened bread, cookies, cakes, couscous and malted beverages, etc.

Even though the crop is robust and versatile, it has faced drawbacks in terms of yield and reduction in acreage due various diseases. The major diseases that affect sorghum include downy mildew, turcicum leaf blight, anthracnose and sorghum smuts (covered kernel smut, loose smut, long smut and head smuts). Turcicum leaf blight (TLB) is one of the most destructive foliar diseases of maize and sorghum. It can cause yield reduction more than $50 \%$ in susceptible varieties and is favoured by mild temperatures and humid weather conditions with heavy dews (Bergquist, 1986). The disease occurs as long elliptic tan lesions that develop on lower leaves and progress upwards. Susceptibility to Exserohilum turcicum is reported to decrease with crop maturity (Frederiksen, 1980).

Most of the composites and hybrids which are being grown on commercial scale are found to be more or less susceptible to TLB. Host plant resistance is considered as most practical, feasible and economical method of plant disease management. Hence, screening of promising sorghum genotypes was undertaken under artificial inoculated conditions to identify source of resistance.

\section{Materials and Methods}

Nearly 23 promising sorghum genotypes were screened under glasshouse conditions by using Pot culture technique (Greenhouse screening technique).

\section{Inoculum preparation}

The fungal isolate was grown in potato dextrose broth in a rotary shaker $\left(25^{\circ} \mathrm{C}, 125\right.$ rpm, with cool light) for 10 days. Conidia were separated from mycelial mat and medium by filtering the cultures through double-layered muslin cloth, and spore was adjusted to concentration $\left(1 \times 10^{5}\right.$ conidia $\mathrm{mL}^{-1}$ ) with the help of haemocytometer. Two drops of Tween- $20^{\mathrm{TM}}$ was added to $100 \mathrm{ml}$ inoculum just before inoculation.

\section{Inoculation}

Inoculum was sprayed on 21-days old plants raised in pots using a hand-held atomizer. The inoculated plants were air dried and 
transferred to a humid chamber for $24 \mathrm{~h}$. Five plants/pot with 3 replications were maintained for each genotype. The plants were transferred to greenhouse benches and the pots were arranged in a complete randomized design and regular watering was provided to maintain high humidity. Data was recorded on latent period (time in days for the appearance of first chlorotic/necrotic lesion) starting the $4^{\text {th }}$ day after inoculation on each genotype. Data was recorded for disease reaction types and disease severity on ( 1 to 5 scale) as described below (Thakur et al., 2007) 14 days after inoculation.

\section{Results and Discussion}

A total of 23 sorghum genotypes were screened for their reaction against turcicum leaf blight under glass house condition.

Table.1 Disease severity (1-5 scale) against E. turcicum (Thakur et al., 2007)

\begin{tabular}{|c|c|c|}
\hline Severity Rating & Symptom and lesion types (on top four leaves) & Reaction type \\
\hline $\mathbf{1}$ & No visible symptoms/chlorotic & Highly resistant (HR) \\
\hline $\mathbf{2}$ & $\begin{array}{c}\text { Up to } 10 \% \text { leaf area covered } \\
\text { with small restricted lesions }\end{array}$ & Resistant (R) \\
\hline $\mathbf{3}$ & $11-25 \%$ leaf area covered with small restricted lesions & Moderately resistant (MR) \\
\hline $\mathbf{4}$ & $26-50 \%$ leaf area covered with large coalescing lesions & Susceptible (S) \\
\hline $\mathbf{5}$ & $>50 \%$ leaf area covered with large coalescing lesions & Highly susceptible (HS) \\
\hline
\end{tabular}

Table.2 Reaction of sorghum genotypes against E. turcicum under glasshouse conditions

\begin{tabular}{|c|c|c|c|}
\hline SL.NO & Genotypes & Grade & Reaction \\
\hline 1 & $J-6-2$ & 3 & MR \\
\hline 2 & $\mathrm{~J}-4-1$ & 3 & MR \\
\hline 3 & $\mathrm{~J}-9-12$ & 3 & MR \\
\hline 4 & $\mathrm{~J}-9$ & 2 & $\mathrm{R}$ \\
\hline 5 & $\mathrm{~J}-35$ & 3 & MR \\
\hline 6 & $\mathrm{~J}-33$ & 3 & MR \\
\hline 7 & C-38 & 3 & MR \\
\hline 8 & C-35 & 3 & MR \\
\hline 9 & C-42 & 2 & $\mathrm{R}$ \\
\hline 10 & C- 28 & 3 & MR \\
\hline 11 & $\mathrm{~J}-11$ & 3 & MR \\
\hline 12 & $\mathrm{~J}-8$ & 3 & MR \\
\hline 13 & $\mathrm{~J}-3-1$ & 3 & MR \\
\hline \multicolumn{4}{|c|}{ Checks } \\
\hline 14 & GS-23 & 3 & MR \\
\hline 15 & Chincholli & 3 & MR \\
\hline 16 & DSV-4 & 4 & $\mathrm{~S}$ \\
\hline 17 & E-36-1 & 3 & MR \\
\hline 18 & $J-P-1-5$ & 2 & $\mathrm{R}$ \\
\hline 19 & DJ-6514 & 4 & $\mathrm{~S}$ \\
\hline 20 & SPV-86 & 4 & $\mathrm{~S}$ \\
\hline 21 & IS-2312 (Resistant Check) & 2 & $\mathrm{R}$ \\
\hline 22 & H-112 (Susceptible check) & 4 & $\mathrm{~S}$ \\
\hline 23 & M 35-1 & 3 & MR \\
\hline
\end{tabular}

R-Resistant, MR-Moderately resistant, S-Susceptible 
The results reveals that, Out of 23 genotypes screened, four showed resistant reaction (Grade-2) viz., J-P-1-5, J-9, IS-2312 and C42. Whereas M 35-1, J-33, J-3-1, J-4-1, Chincholli, GS-23, E-36-1, J-35, C-35, J-912, J-6-2, J-11, C-30, J-8 and C-28 showed moderately resistant reaction (Grade-3) and remaining four genotypes viz., DSV-4, SPV86, DJ-6514, H-112 recorded susceptible reaction (Grade-4) indicating their susceptibility for TLB under glasshouse condition (Table 1 and 2).

These are in agreement with results obtained by earlier workers (Vaibhav and Yogendra 2014) while working with turcicum leaf blight of sorghum who found 39 germplasms showed resistant reaction which included SPV 2019, SPV 2024, SPH 1653, SPV 2020 and SPV 2021; 43 showed moderately resistant reaction while 11 were recorded as susceptible. Moderately resistant germplasms included SPV 1822, SPV 2011, CSH 23, SPV 1871, SPV 2027 and SPV 2010.

\section{References}

Anonymous, 2014-15, Directorate of Economics and Statistic Bengaluru. High power committee report. pp: 6874.

Bergquist, R., 1986., Leaf blight, In: Compendium of Sorghum Diseases. American Phytopathological Society., 48:56-58.

Burke, J.J., Franks, C.D., Burrow, G. and Xin. Z. 2010. Selection system for the stay green drought tolerance trait in sorghum germplasm. Agron. J., 102: 1118-1122.

Dicko, M.H., Gruppen, H., Zouzouho, O. C., Traore. A. S., Berkel, W. J. and Voragen, A. G. J., 2006, Effect of germination on amylases and phenolics related enzymes in fifty sorghum verities grouped according to food-end use properties. J. Sci. Food Agric., 86:130-143.

Frederiksen, R.A., 1980. Sorghum leaf blight. In Proceedings of the International Workshop on Sorghum Diseases: 1115 Dec. 1978, Hyderabad, ICRISAT, Patancheru, A.P. 502324, India. pp. 243-248.

FAOSTAT, 2014, World Sorghum production and utilization. FAO Rome. Available on http://www.faostat.fao.org./ foodgrains.

INDISTSAT 2015, India sorghum production and utilization. New Delhi. Available on http://www.indiastat.com/agri culture/2/foodgrains/17180/jowargreat millet.

Thakur, R.P., Reddy, B. V. S. and Mathur, K., 2007, Screening techniques for sorghum diseases. Information Bulletin No. 76. International Crops Research Institute for the Semi-Arid Tropics. 92 pp.

Vaibhav, S., and Yogendra, S., 2014, Screening of germplasm against Exserohilum leaf blight. Indian Journal Of Animal Nutrition, 7(16): 2087-2089.

\section{How to cite this article:}

Raghavender Yelgurty, S.K. Jayalkshmi, B. Zaheer Ahamed, Shreedevi S. Chavan and Girish, G. 2019. Screening of Promising Sorghum Genotypes against Turcicum Leaf Blight (Exserohilum turcicum (Pass.) Leonard and Suggs) under Glasshouse Conditions. Int.J.Curr.Microbiol.App.Sci. 8(05): 655-658. doi: https://doi.org/10.20546/ijcmas.2019.805.076 